\title{
Methylene blue decolorization fungi from crude oil contaminated soils
}

\author{
IRVAN PERMANA, AMIR AWALUDDIN, SARYONO ${ }^{\vee}$ \\ Department of Chemistry, Faculty of Mathematics and Natural Sciences, Universitas Riau. Jl. Pekanbaru-Bangkinang Km 12.5, Kampus Bina Widya, \\ Pekanbaru 28293, Riau, Indonesia. Tel.: +62-761-63266, Fax.: +62-761-63279, `email: saryono@lecturer.unri.ac.id, ierphan.permana@gmail.com
}

Manuscript received: 18 June 2019. Revision accepted: 27 August 2019.

\begin{abstract}
Permana I, Awaluddin A, Saryono. 2019. Methylene blue decolorization fungi from crude oil-contaminated soils. Biodiversitas 20: 2693-2697. One of the world problems is the treatment to remove dyes in textile wastewater. Nowadays, the most effective and compatible method to the environment is decolorization by microorganisms. Therefore, the objective of this study is to find out the best fungi to decolorize synthetic dye methylene blue (MB). Total eight fungi that isolated from crude oil-contaminated soil were analyzed to study the effect of various parameters such as $\mathrm{pH}$, the concentration of dyes, contact times and agitation on their rate of reaction. The initial screening showed that Penicillium sp. FTM7 had greater potential in biodegradation the MB. The optimum decolorization of MB by Penicillium sp. was found after 8 days incubation with agitation $150 \mathrm{rpm}$ and concentration of $\mathrm{MB}$ is $40 \mathrm{ppm}$ and unadjusted $\mathrm{pH}(95.45 \%)$. The decolorization of $\mathrm{MB}$ was found to follow first-order reactions.
\end{abstract}

Keywords: Biodegradation, fungi, methylene blue

\section{INTRODUCTION}

Due to rapid industrialization and urbanization, a lot of chemicals including dyes are manufactured and are being used in almost every day. Industries worldwide have witnessed tremendous growth over the years in the use of synthetic dyes. Synthetic dyes are widely used by several industries such as textiles, leather, cosmetics, paper, printing materials and plastics. About 280,000 tons of textile dyes are discharged in industrial effluents every year. There are 20-30\% unfixed reactive dyes applied, with an average concentration of about 2,000 ppm. The release of these pollutants into the environment is undesirable due to the serious environmental problems linked with the dyes and their breakdown products. The most contaminants applied in the industry is azo dyes. These dyes are complex chemical structure confers on them the ability to remain recalcitrant to degradation in water and soil, even possess carcinogenic properties due to their azo bond $(-\mathrm{N}=\mathrm{N}-)$. It has also had a negative impact to water environment like depletion of dissolved oxygen (DO), also cause an adverse impact on total organic carbon (TOC), biological oxygen demand (BOD) and chemical oxygen demand (COD) (Kumar et al. 2016). Among of dyes, methylene blue (MB) includes the dye classification of thiazine. MB is cationic dye as it forms positively charged molecules when dissolved in water. In another application MB also used as medicine. Some diseases that use MB in treatment are Duck hepatitis B and Psoriasis. Also, there is negative effect occurs when contact with MB. It may cause increased heart rate, nausea, Heinz body formation, headache and gastritis. MB resistant to degraded by environmental activities and cause unpleasant sight to the water bodies due to their intense color (Dahri et al. 2015).

Dyes in the environment are always difficult to degrade or decolorize by many known chemical and physical methods. Currently, the physical and chemical treatments are available and applicable to remove dyes from wastewater. Such as adsorption, coagulation, and membrane process, electrochemical methods, advanced oxidation processes (photochemical and photo-catalytic process). Unfortunately, several of them have disadvantages such as use more energy, expensive cost, limited applicability, cause secondary pollution problems in the form of sludge after treatment and toxic reagent also employed (Yang et al. 2016). Among these methods, degradation decolorization by a biological method is more interesting due to low energy cost, inexpensive, specificity, producing less amount of sludge, ease of control and environmental friendly process (Shanmugam and Ulaganathan 2017).

Many studies reported had great results due to the degradation of synthetic dye by biological methods. Research on the fungal degradation of dye has been performed in recent years. Several fungi with the capability to degrade dyes have been reported. For example, Peyronellaea prosopidis was able to degrade Scarlet RR dye (Bankole et al. 2018), Aspergillus niger had maximum degradation of the dye basic fuchsin, Phanerochaete chrysosporium had maximum degradation of the dye Nigrosin (Rani et al. 2014), Coriolopsis sp. even had ability to degrade 4 kinds of azo dyes (ponceau 2R, orange $G$, direct blue and biebrich scarlet) (Cheng et al. 2016), Aspergillus flavus and Penicillium canescens were the best active fungal species for degradation of direct blue dye (Hefnawy et al. 2017), Aspergillus terreus had ability to degrade the Methylene blue and Congo Red (Ramamurthy et al. 2013), Trichoderma harzianum was able to degrade triphenylmethane Cresol Red (Nor et al. 2015), Pleurotus ostreatus was able to degrade MB in liquid and solid media (Menezes et al. 2017). Base on the previous studies it was reported that fungi isolated from soil contaminated by 
crude oil had great potential for degradation of crude oil waste. Generally, these fungi had extracellular enzyme (i.e., laccase, lignin peroxidase and manganese peroxidase) that able to degrade such big and complex aromatic compound in crude oil (Sari 2017). White-rot fungus had reported that to have ability degrade dyes in textile effluent and the enzymes that play important roles in the biodegradation process are laccase, manganese peroxidase and lignin peroxidase (Mustafa et al. 2017).

Accordingly, the objective of this study is to evaluate the biodegradation of Methylene Blue by fungi that isolated from soil contaminated by crude oil.

\section{MATERIALS AND METHODS}

\section{Materials}

Potato Dextrose Agar (PDA; 20\% potato, 2\% dextrose and $2 \%$ agar) medium was used to grow the fungal cultures. Potato Dextrose Broth (PDB; $20 \%$ potato, 2\% dextrose) used for liquid fungal culture (Saryono et al. 2016). Dye-containing PDA was prepared with PDA medium and the addition of $\mathrm{MB}$ solution to reach concentration $1,000 \mathrm{mg} / \mathrm{L}$. The chemicals used were $\mathrm{NaOH}$ $0.5 \mathrm{~N}, \mathrm{HCl} 0.5 \mathrm{~N}$, aquadest (neutral $\mathrm{pH}$ ), ethanol $70 \%$, and methylene blue dye that was purchased from Merck and used without further purification.

\section{Microorganisms}

The fungi used in this study were isolated previous study by Sari (2017). Pure culture of each fungus isolated was maintained at Biochemical Laboratory UR. Eight fungi namely Fusarium sp. (FTM1), Penicillium sp. (FTM2), Trichoderma sp. (FTM3), Penicillium sp. (FTM4), Aspergillus sp. (FTM5), Aspergillus sp. (FTM6), Penicillium sp. (FTM7), Aspergillus sp. (FTM8). Slants of these fungi were in the test tubes with PDA medium and kept for further use.

\section{Procedures}

\section{Calibration of dye solution}

The dye solutions were initially calibrated for concentration in terms of absorbance units. Each of the standard dye solution $(100 \mathrm{mg} / \mathrm{L})$ was diluted with distilled water to concentrations of $0,1.0,2.0,4.0,6.0,8.0$ and 10.0 $\mathrm{mg} / \mathrm{L}$, respectively. Each concentration of solutions was measured for its absorbance value at its corresponding $\lambda_{\max }$. The absorbance values versus concentrations were then plotted.

\section{Initial screening}

A mycelium disc from the fungi strains that grown on PDA medium plates after 2 days at room temperature was inoculated into the center of the petri dish that filled by dye-containing PDA medium. The plates were incubated at room temperature for 7 days. The ability of the fungi to degrade the MB was determined by the outside diameter of clear zone in PDA medium (mm). The fungi strain giving maximum outside diameter of the clear zone was selected and used for further experiments.

\section{Experimental method}

The fungi that showed a decolorized zone of strain on the solid media were taken out for next testing in liquid media. Degradation of MB dye was carried out under 150 rpm agitation condition with $100 \mathrm{~mL}$ culture of fungi pregrown on PDB. The dye $(1,000 \mathrm{mg} / \mathrm{L})$ was added into each $250 \mathrm{~mL}$ Erlenmeyer flask containing $100 \mathrm{~mL}$ of individual pre-grown cultures of fungi and further incubated until degradation was observed in 0 until 8 days. About $5 \mathrm{~mL}$ aliquots of the culture supernatant were withdrawn at regular time intervals during the process of degradation. A 3,000 rpm centrifugation for 15 minutes was carried out to separate the fungi cell mass (Bankole et al. 2018). The degradation was monitored by measuring the change in absorbance maximum of the dye ( $\lambda_{\max }$ methylene blue was $655 \mathrm{~nm}$ ) using a spectrophotometer Thermo Scientific Genesys 10S UV-Vis. The percentage of degradation was calculated using the following formula:

$$
\% \text { Degradation }=\frac{\text { Initial absorbance }- \text { final absorbance }}{\text { Initial absorbance }} \times 100
$$

The effect of various physicochemical conditions such as $\mathrm{pH}(4.0,6.0,8.0$ and 10.0), contact time $(2,4,6$ and 8 days), agitation $(0,100$ and $150 \mathrm{rpm})$ and $\mathrm{MB}$ initial concentration $(20,40,60,80$ and $100 \mathrm{ppm})$ by the isolate were also studied.

\section{RESULTS AND DISCUSSION}

\section{Initial screening}

The biodegradation capability of eight fungi that isolated from crude oil-contaminated soil was assessed on dye-containing PDA plates with synthetic dyes inoculated at room temperature for one week. The dye biodegradation results on agar plates showed that three fungi strains had high abilities to decolorize MB. These fungi were FTM2, FTM6 and FTM7 had potential to decolorize MB (Figure 1).

\section{Biodegradation of MB by fungi}

The effect of various physicochemical conditions like contact time, initial concentration, agitation and $\mathrm{pH}$ on degradation of MB was studied in detail. Effect of contact time on the removal of dye MB is shown in Figure 3. The dye removal process begins at 0 days. Generally, degradation of MB by all fungi sharply increased by 0 days and it gradually increased until it reached $94.20 \%$ at 8 days. Increasing the initial concentration provides more driving force to overcome the mass transfer resistance between the solid phase and the liquid phase (Dahri et al. 2015). Figure 4. shown the effect of agitation towards ability of FTM7 to degrade MB. It is clear that fungi FTM7 had maximum $94.20 \%$ dye degradation ability at $150 \mathrm{rpm}, 81.21 \%$ at 100 rpm and in static condition was $64.59 \%$. Effects of MB initial concentration toward degradation of $\mathrm{MB}$ by fungi showed by Figure 5 which indicates that there is no significant different percentage of dyes degradation with the increasing initial concentration of dyes. Otherwise, these fungi able to achieve $95.45 \%$ degradation of $\mathrm{MB}$ at 
$40 \mathrm{ppm}$. The biodegradation of MB by fungi FTM7 was affected by changes of $\mathrm{pH}$ as shown in Figure 6. The range of $\mathrm{pH}$ studies used for MB was 4.0-10.0. It has shown the most significant degradation MB obtained in $\mathrm{pH}$ 6.0.

\section{Kinetic study}

Kinetics is an important parameter to evaluate the performance of fungi to degrade MB. Generally, the kinetic study determined by linear regressions of degradation time versus $\mathrm{MB}$ concentration depends on kinds of order reaction. MB concentration can be obtained from the linear equation in calibration graphic (Figure 2). When looking at the linearity coefficient $\left(\mathrm{R}^{2}\right)$ for three models of order reaction (Table 1), it can be concluded that the first-order reaction had $\mathrm{R}^{2}$ bigger than the others. It is assumed that the degradation rate of $\mathrm{MB}$ was effected by $\mathrm{MB}$ concentration.

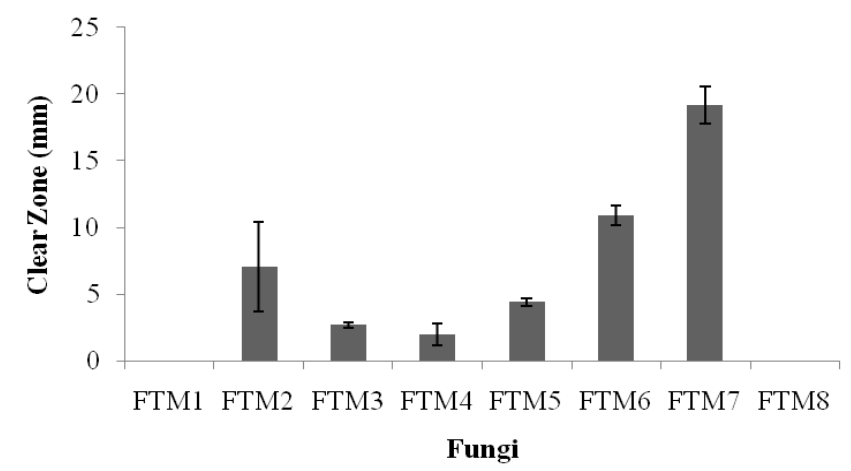

Figure 1. Initial screening MB degradation

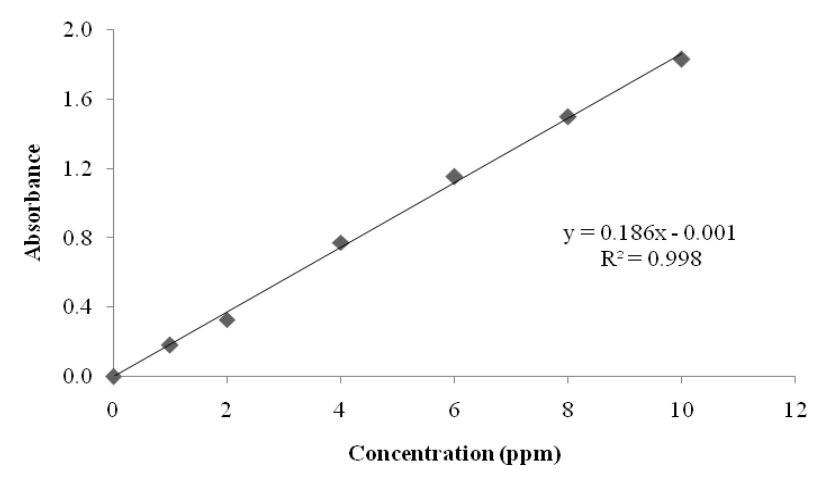

Figure 2. MB calibration graphic

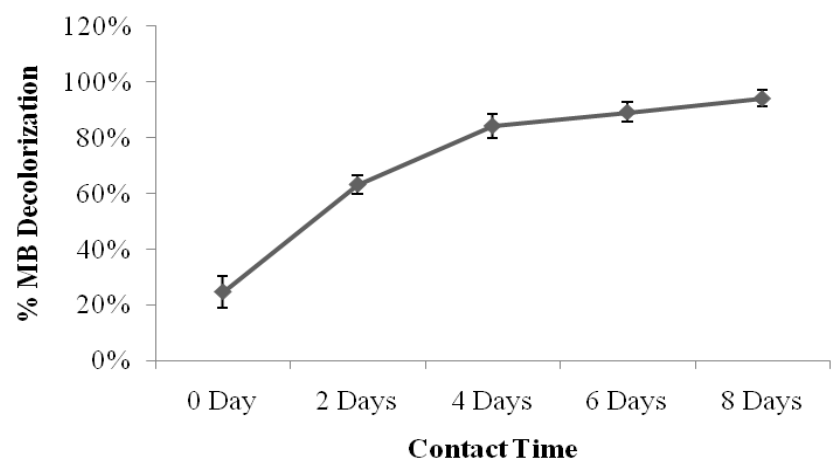

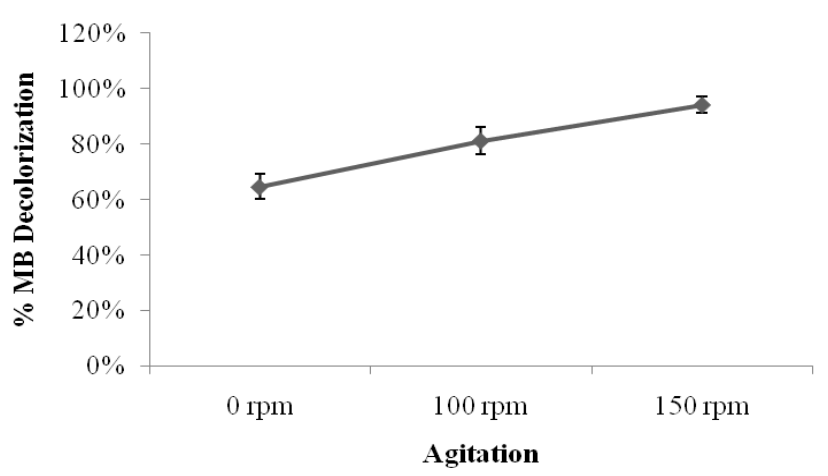

Figure 4. Effect of agitation

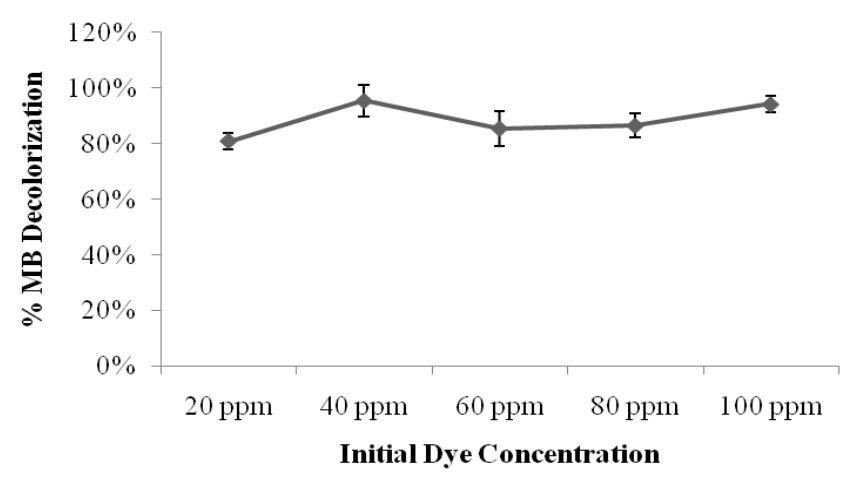

Figure 5. Effect of MB Initial Concentration

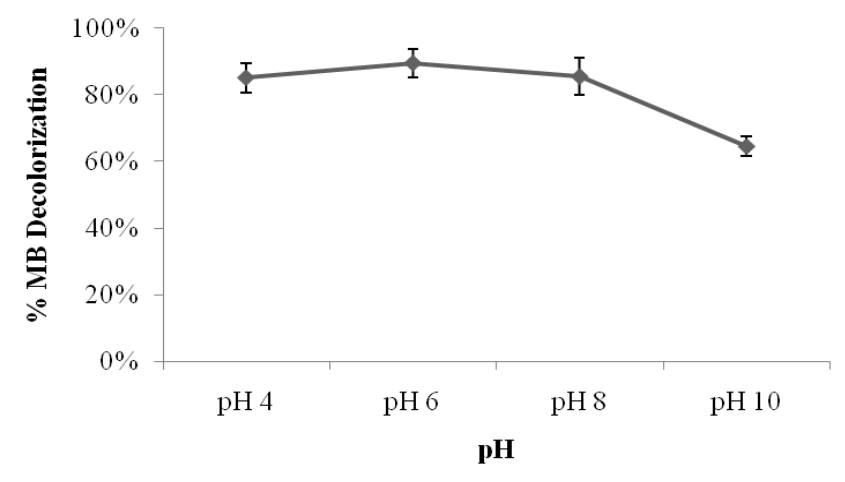

Figure 6. Effect of $\mathrm{pH}$

Table 1. Means of $\mathrm{R}^{2} \mathrm{MB}$ degradation for various parameters and conditions.

\begin{tabular}{cccc}
\hline \multirow{2}{*}{ Fungi } & \multicolumn{3}{c}{ Linearity Coefficient $\left(\mathbf{R}^{\mathbf{2}}\right)$} \\
\cline { 2 - 4 } & Zero Order & First Order & Second Order \\
\hline FTM7 & 0.899 & 0.903 & 0.794 \\
\hline
\end{tabular}

Figure 3. Effect of contact times 


\section{Discussion}

The previous study reported that there are eight fungi had been isolated from crude oil-contaminated soil. These fungi also had great potential to degrade big and complex aromatic compound in crude oil. These fungi were Fusarium sp. (FTM1), Penicillium sp. (FTM2), Trichoderma sp. (FTM3), Penicillium sp. (FTM4), Aspergillus sp. (FTM5), Aspergillus sp. (FTM6), Penicillium sp. (FTM7), Aspergillus sp. (FTM8) (Sari 2017). The initial screening of fungi for dye biodegradation via solid medium was identified by a clear zone surrounding the fungal colonies. It was used to determine the greatest potential of fungi to degrade MB. The highest dye degradation was detected in fungi FTM7 that of remaining 7 fungi. The clear zone that appears in around the colonies indicated that fungi FTM7 is able to degrade MB. The clear zone also signs that the biosorption degradation mechanism used by fungi (Park et al. 2006). These results also indicated that these fungi have enzymatic system for breaking organic complex structures. The dry weight biomass of this fungus with MB dye after treatment may have been due to a reaction of MB with enzymes secreted by the fungal mycelia. The previous study also reported that Penicillium funigulosum showed higher dyes removal activity towards MB (AI-Jawhari 2015). Afterward, fungi FTM7 selected for further studies.

Effect of contact time. Dye degradation time is a crucial parameter to be considered as it can determine the energy and cost of the removal process. In this study, the effect of contact time was investigated. The highest dye degradation was observed at contact time eight days. Longer time is taken to remove the dye also increases the cost of energy to supplied (Chen et al. 2015). This results reported that the capacity of $\mathrm{MB}$ degradation by fungi increased with an increase in contact time. However, the previous study reported that the fungal strain isolated from soils contaminated with dyes shown higher dyes degradation within 120 hours. The fungi were identified as Penicillium oxalicum SAR-3 based on $18 \mathrm{~S}$ and internal transcribed spacer (ITS) rDNA gene sequence analysis (Saroj et al. 2014). The previous study also found that the enzyme laccase that isolated from fungus Aspergillus oryzae able to degrade $53 \%$ of $\mathrm{MB}$ after 30 minutes incubation (Forootanfar et al. 2012). Another study reported that consortium fungal-bacterial Aspergillus ochraceus NCIM1146 and Pseudomonas sp. SUK1 was also able to degrade azo dye rubine GFL 95\% in 30 hours (Lade et al. 2012). Nonetheless, these results need to improve degradation time due to the efficiency and effectiveness of time and energy. The different method even reported that dyes degradation by using AOP method only need 120 minutes to oxidize methylene blue into benign products such as $\mathrm{CO}_{2}$ and $\mathrm{H}_{2} \mathrm{O}$ (Zulfa et al. 2018).

Effect of agitation. The MB degradation by fungi FTM7 was evaluated at 0,100 and $150 \mathrm{rpm}$. The results showed that the highest dye degradation was observed at agitation $150 \mathrm{rpm}$. Similar findings was observed in the previous study in which a novel white-rot fungi Alternaria alternata CMERI F6 reported to decolorized $99.99 \%$ of $600 \mathrm{mg} / \mathrm{L}$ congo red within 48 hours at $150 \mathrm{rpm}$ (Chakraborty et al.
2013). It is due to aeration and agitation which is necessary to fulfill the microbial oxygen requirements during the cultivation and to enhance the oxygen gas-liquid mass transfer. This might affect the morphology of filamentous fungi and lead to an increased rate of enzyme synthesis (Irpex 2006). In contrast, another study reported that activities of Aspergillus niger and Penicillium spp. on the decolorization of the dye solution was more efficient in the static condition than the shaking condition (Sh 2008). Degradation performance of Scarlet $\mathrm{R}$ was $100 \%$ under static condition after certain incubation period with the consortium-GR (consisting of Proteus vulgaris NCIM2027 and Micrococcus glutamicus NCIM-2168) (Saratale et al. 2009).

Effect of initial concentration. The concentration of dye can influence the efficiency of dye removal through a combination of factors including the toxicity of the dye at higher concentrations and the ability of the enzyme to recognize the dye efficiently at very low concentrations (Wanyonyi et al. 2019). The degradation percentage of methylene blue by fungi FTM7 was studied at different initial dye concentrations range from 20 to $100 \mathrm{mg} / \mathrm{L}$. The results showed that the degradation rate affected by initial dye concentration slightly. A difference reported in a previous study revealed that the decolorization rate of dye decreased with increasing initial dye concentration (Daâssi et al. 2013). Similar results also reported that microorganisms also could decolorize reactive brilliant red $99 \%$ at concentration small than $200 \mathrm{mg} / \mathrm{L}$. However, above this concentration, dye decolorization decreased about $20 \%$ at initial concentration was $1,000 \mathrm{mg} / \mathrm{L}$ (Chang et al. 2017). Decrease in degradation rate of Lentinus crinitus fungi was observed with the increase in initial dye concentration (Heyse et al. 2010). It happens due to high toxicity properties of dye towards microorganisms at high concentrations (Chen et al. 2015).

Effect of $\mathrm{pH}$. It is important to study the effect of $\mathrm{pH}$ on degradation process, as transport of dye molecule into the cell is $\mathrm{pH}$ dependent and thought to be rate-limiting step for degradation of dyes The results showed that FTM7 had the highest degradation activity at $\mathrm{pH} 6.0$, and the $\mathrm{MB}$ degradation decreases with increase in $\mathrm{pH}$. It is similar to fungus Sphingomonas paucimobilis that had maximum dye degradation ability at $\mathrm{pH} 6-7$, while condition moves to more acid and alkaline the decolorization efficiency decreases (Bunti et al. 2017). The previous study also reported that general fungi and yeast showed optimum degradation in acid or neutral conditions (Hazrat 2010). It is also similar for fungi Phanerochaete chrysosporium that able to degrade synthetic dye in acid conditions and had optimum decolorization at $\mathrm{pH}$ 5.0. In highly acid conditions, a decrease in decolorization rate may be due to a decrease in enzymatic activity when $\mathrm{pH}$ changed from optimum levels (Sharma et al. 2009).

Kinetic study. In the present study, the kinetics of MB degradation for different environmental conditions was modeled using zero, first and second-order kinetics models. Zero-order reaction plots were obtained by plotting dye concentration versus time, first-order reaction plot was obtained by plotting $\ln$ (concentration) against time and 
second-order reaction model obtained by plotting $1 /$ concentration versus time (Wanyonyi et al. 2019). The results showed that degradation of MB by fungi FTM7 was first-order reaction. Another study also reported that photodegradation methylene blue by $\mathrm{TiO}_{2}$ catalyst followed first-order reaction (Sumerta et al. 2002).

In the end, the conclusion of the study was that Fungi FTM7 had the greatest potential to degrade methylene blue (MB) and the optimum degradation has been found at 8 days incubation period, agitation $150 \mathrm{rpm}$, the initial concentration of $\mathrm{MB}$ was $40 \mathrm{ppm}$ and unadjusted $\mathrm{pH}$ condition.

\section{REFERENCES}

Al-Jawhari IFH. 2015. Decolorization of methylene blue and crystal violet by some filamentous fungi. Sci Educat Publ 3 (2): 62-65.

Bankole PO, Adekunle AA, Obidi OF, Chandanshive VV, Govindwar SP. 2018. Biodegradation and detoxification of Scarlet RR dye by a newly isolated filamentous fungus, Peyronellaea prosopidis. Sustain Environ Res 25: 214-222.

Buntic AV, Pavlovic MD, Antonovic DG, Siler-Marinkovic SS Dimitrijevic SI. 2017. Treatment of wastewater containing basic dyes by the use of new strain Streptomyces microflavus CKS6. Journal of Cleaner Production 148: 347-354.

Chakraborty S, Bask B, Dutta S, Bhunia B, Dey A. 2013. Decolorization and biodegradation of Congo red dye by a novel white rot fungus Alternaria alternata CMERI F6. Bioresour Technol 147: 662-666.

Chang J, Saratale RG, Saratale GD, Chang JS, Govindwar SP. 2017. Decolorization and biodegradation of textile dye Navy blue HER by Trichosporon beigelii NCIM-3326. J Hazard Mater 166: 1421-1428.

Chen SH, Su A, Ting Y. 2015. Biosorption and biodegradation potential of triphenylmethane dyes by newly discovered Penicillium simplicissimum isolated from indoor wastewater sample. Intl Biodeterior Biodegrad 103: 1-7.

Cheng WN, Sim HK, Ahmad SA, Shukor MY, Yusof MT. 2016 Characterization of an azo dye degrading white root fungus isolated from Malaysia. Mychosphere 7: 560-569.

Daâssi D, Mechichi T, Nasri M, Rodriguez-couto S. 2013. Decolorization of the metal textile dye lanaset grey $\mathrm{G}$ by immobilized white-rot fungi. J Environ Manag 129: 324-332.

Dahri MK, Kooh MRR, Lim LBL. 2015. Application of Casuarina equisetifolia needle for the removal of methylene blue and malachite green dyes from aqueous solution. Alexandria Eng J 54: 1253-1263.

Forootanfar H, Moezzi A, Aghaie-khozani M, Mahmoudjanlou Y, Ameri A, Niknejad F, Faramarzi MA. 2012. Synthetic dye decolorization by three sources of fungal laccase. Iranian J Environ Health Sci Eng. 9 (1): $1-10$.

Hazrat A. 2010. Biodegradation of synthetic dyes - A Review. Water Air Soil Pollut 213: 251-273.

Hefnawy MA, Gharieb MM, Shaaban MT, Soliman AM. 2017. Optimization of culture condition for enhanced decolorization of direct blue dye by Aspergillus flavus and Penicillium canescens. J Appl Pharmaceut Sci 7: 083-092.

Heyse C, Knoll A, Schadeck R, Mitchell DA, Kava-cordeiro V, Paba J. 2010. Decolorization and biodegradation of reactive blue 220 textile dye by Lentinus crinitus extracellular extract. J Hazard Mater 180 (13): 316-322.

Husseiny Sh. M. 2008. Biodegradation of the reactive and direct dyes using Egyptian isolates. J Appl Sci Res 4 (6): 599-606.

Irpex I, Tavčar M, Kuplenk J, Pavko A. 2006. Biodegradation of azo dye RO16 in different reactors by immobilized Irpex lacteus. Acta Chim Slov 53: 338-343.
Kamal R, Babu V, Philip L, Ramanujam S. 2016. Applicability of pulsed power technique for the degradation of methylene blue. J Water Process Eng 11: 118-129.

Kumar S, Raut S, Bandyopadhyay P. 2016. Fungal decoloration and degradation of azo dyes: A Review. Fungal Biol Rev 30: 112-133.

Lade HS, Waghmode TR, Kadam AA, Govindwar SP. 2012. Enhanced biodegradation and detoxification of disperse azo dye Rubine GFL and textile industry effluent by defined fungal-bacterial consortium. Intl Biodeterior Biodegrad 72: 94-107.

Menezes S, Almeida S, Sussuchi EM, Roberto P, Vi A, Marino RH. 2017. Bioremediation potential of filamentous fungi in methylene blue: solid and liquid culture media. Lavras. 41 (5): 526-532.

Mustafa MM, Jamal P, Alkhatib MF, Mahmod SS, Jimat DN, Ilyas NN. 2017. Panus tigrinus as a potential biomass source for Reactive Blue decolorization: Isotherm and kinetic study. Electr J Biotechnol 26: 711.

Nor NM, Hadibarata T, Mohd M, Ahmad F. 2015. Mechanism of triphenylmethane cresol red degradation by Trichoderma harzianum M06. Bioprocess Biosyst Eng. 38: 2167-2175.

Park C, Lee M, Lee B, Kim S, Chase HA, Lee J, Kim S. 2006. Biodegradation and biosorption for decolorization of synthetic dyes by Funalia trogii. Biochem Eng J 36: 59-65.

Ramamurthy V, Umamaheswari G, Nadu T, Nadu T. 2013. Biodegradation of synthetic dyes by Aspergillus terreus inoculated on solid media. Intl J Innov Res Sci Eng Technol 2 (12): 7821-7827.

Rani B, Kumar V, Singh J, Bisht S, Teotia P, Sharma S, Kela R. 2014. Bioremediation of dyes by fungi isolated from contaminated dye effluent sites for bio-usability. Brazilian J Microbiol 45: 1055-1063.

Saryono, Firiani, Soedjanaatmadja U. 2016. Beberapa mirkoorganisme yang menghasilkan enzim inulinase, isolasi dan karakterisasi enzim dari aspergillus flavus gmn 11.2 galur lokal. Chem Nat Acta 4: 165174.

Sari EM. 2017. Uji Efektivitas Jamur Indigenus Pendegradasi Hidrokarbon Minyak Bumi Yang Diisolasi Dari Tanah Tercemar Tumpahan Minyak Bumi. [Thesis]. Universitas Riau, Pekanbaru. [Indonesian].

Saroj S, Kumar K, Pareek N, Prasad R, Singh RP. 2014. Biodegradation of azo dyes acid red 183, direct blue 15 and direct red 75 by the isolate Penicillium oxalicum SAR-3. Chemosphere 107: 240-248.

Saratale RG, Saratale GD, Kalyani DC, Chang JS, Govindwar SP. 2009. Enhanced decolorization and biodegradation of textile azo dye Scarlet $\mathrm{R}$ by using developed microbial consortium-GR. Bioresour Technol 100: 2493: 2500 .

Shanmugam S, Ulaganathan P. 2017. Enhanced biodegradation and detoxification of malachite green by Trichoderma asperellum laccase: Degradation pathway and product analysis. Intl Biodeterior Biodegrad 125: 258-268.

Sharma P, Singh L, Dilbaghi N. 2009. Biodegradation of Orange II dye by Phanerochaete chrysosporium in simulated wastewater. Journal of Scientific \& Industrial Research 68: 157-161.

Sumerta IK, Wijaya K, Tahir I. 2002. Fotodegradasi metilen biru menggunakan katalis $\mathrm{Ti}_{-} \mathrm{O}_{2}$ montmorilonit dan sinar UV. Seminar Nasional Pendidikan Kimia UNY, Yogyakarta. [Indonesian]

Wanyonyi WC, Onyari JM, Shiundu, PM, Mulaa FJ. 2019. Effective biotransformation of Reactive Black 5 Dye Using Crude Protease from Bacillus Cereus Strain KM201428. Energy Procedia 157: 815824.

Yang P, Shi W, Wang H, Liu H. 2016. Screening of freshwater fungi for decolorizing multiple synthetic dyes. Brazilian J Microbiol 47: 828834.

Yu Z, Wen X. 2005. Screening and identification of yeasts for decolorizing synthetic dyes in industrial wastewater. Intl Biodeterior Biodegrad 56: 109-114.

Zulfa Z, Absus S, Awaluddin A, Anita S, Siregar SS, Zulfikri. 2018. Effect of precursors on morphology and catalytic activities of binnersite for methylene blue degradation. J Physics Conf Ser 1097: $1-9$. 